\title{
Creating a younger smile through orthodontic treatment*
}

\section{Delphine Haggiag-Grimbert}

\section{Directeur de mémoire : Edith LEJOYEUX / Paris VII}

\author{
ABSTRACT
}

More and more adults are beginning orthodontic treatment because they want to regain the smile they had when they were 20 years-old and to diminish the signs of aging their faces present to degrees that depend upon the severity of their dento-facial deformity.

The dental esthetic criteria that are sought after and regained with treatment are, primarily straightening and whitening of teeth, and a smooth appearance of the teeth and their mutual contours, predominantly in the upper incisor area as well as a regular, broad smile line in harmony with the lower lip. In addition to these dental guide lines, additional important consideration should be taken of the relationship of the size and bulk of the teeth with respect to facial type and the absence of any strain in lip posture.

Orthodontic treatment, in correcting malocclusions of varying severity, can effectively join with other specialties in creating a younger smile line for patients and eliminating many signs of aging.

\section{KEYWORDS}

Orthodontics

Smiling

Restoring youthful appearance

Clinical cases

\section{Address for correspondence: \\ D. HAGGIAGGRIMBERT, \\ 4, rue La Pérouse, \\ 75116 Paris. \\ dhaggiag@hotmail.com}

* The English version of this paper is not available; to read the French version, go to http://odf.edpsciences.org/10.1051/odf/2009002 